\title{
13 RELATIONSHIP BETWEEN BONE MINERAL CONTENT, BONE MINERAL DENSITY AND ANAEROBIC POWER IN PROFESSIONAL JUMPERS
}

Mahdi Haydari, Nader Rahnama, Khalil Khayambashi, Mohammad Marandi Faculty of Physical Education and Sport Sciences, University of Isfahan, Isfahan, Iran

10.1136/bjsm.2010.078725.13

The positive effect of physical activity and exercise on bone mass is well documented in several studies comparing with sedentary subjects. Recent studies have reported that cardiovascular fitness and weight-bearing exercise affect bone mass beneficially. Although it is widely accepted that muscle strength is significantly correlated with bone mass, little is known about anaerobic power and its relation to bone mass. Therefore, the purpose of this study was to analyse the relation between bone mass and anaerobic power in professional jumpers. Thirty professional men jumpers (long, high and triple jumping) with no history of bone disease participated in this study (mean $\pm S D$, aged $21.27 \pm 3.52$ years, height $182 \pm 6 \mathrm{~cm}$, weight $69.93 \pm 6.01 \mathrm{~kg})$. Bone mineral content (BMC) and bone mineral density (BMD) were measured by dual-energy x-ray absorptiometry. Femoral neck and trochanter BMC and BMD for right and left sides and also lumbar spines were assessed. Sargent jump test was performed by athletes and records were converted to anaerobic power using Lewis formulae. Pearson correlation test was used to analyse data. Results of this study showed a positive relationship between femoral neck and trochanter BMC and anaerobic power $(r=0.557, \mathrm{p}<0.05)$. Similar result was found for femoral neck and trochanter $\mathrm{BMD}$ and anaerobic power $(r=0.446, p<0.05)$. In conclusion, long-term jumping, is associated with markedly increased $\mathrm{BMC}$ and $\mathrm{BMD}$ at the femoral neck and trochanter and it can be accounted as one of the important environmental factors to determine femoral BMC and BMD in elite jumpers. 